Journal of Sustainable Development of Transport and Logistics

journal home page: https://jsdtl.sciview.net

Jayarathna, D. G. N. D., Lanel, G. H. J., \& Juman, Z. A. M. S. (2021). Modeling a cost benefit

transportation model to optimize the redistribution process: Evidence study from Sri

Lanka. Journal of Sustainable Development of Transport and Logistics, 6(2), 43-59.

doi:10.14254/jsdtl.2021.6-2.3.

\title{
Modeling a cost benefit transportation model to optimize the redistribution process: Evidence study from Sri Lanka
}

\author{
D. G. N. D. Jayarathna *(D), G. H. J. Lanel $* * \mathbb{D}$, Z. A. M. S. Juman $* * * \mathbb{D}$ \\ ${ }^{*}$ Colombo International Nautical and Engineering College, \\ IT Park, Millennium Dr, Malabe, Sri Lanka \\ nuwan.djsh@gmail.com \\ ${ }^{* *}$ University of Sri Jayewardenepura, \\ Gangodawila, Nugegoda, Sri Lanka \\ Department of Mathematics \\ ghjlanel@sjp.ac.lk \\ ${ }^{* * *}$ University of Peradeniya, \\ Peradeniya, 20400, Sri Lanka \\ Department of Mathematics, Faculty of Science \\ jumanabdeen@yahoo.com
}

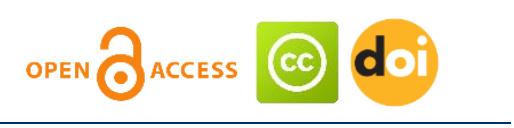

\section{Article history:}

Received: March 17, 2021

1st Revision: August 23,

2021

Accepted: November 05, 2021

\section{DOI:}

10.14254/jsdtl.2021.6-2.3

\begin{abstract}
This study is a case study based on Softlogic Retail (Pvt) Ltd, Sri Lanka, which is a famous consumer electronics company and market leader in Sri Lanka. This company's outbound logistics have been considered in this research, and they are mainly forced into the redistribution process in Sri Lanka. Extra routing costs due to unreasonable consumption of additional distance have been noticed in the current redistribution process. Here, this problem is modeled as a variant of the vehicle routing problem with a heterogeneous vehicle fleet. Our objective is to minimize warehouse operation, administration, and transportation costs by imposing constraints on capacity and volume. The researchers propose new heuristic solutions to the problem. A proposed heuristic algorithm has been used to find the optimal path between clusters. The computational investigation highlights the cost savings that can be accrued by this new heuristic. The cost savings can be accrued at a rate of as much as $37.5 \%$ compared to the company's existing method.
\end{abstract}

Keywords: vehicle routing problem, heterogeneous vehicle fleet, redistribution process, heuristic method.

Corresponding author: D. G. N. D. Jayarathna

E-mail: nuwan.djsh@gmail.com

This open access article is distributed under a Creative Commons Attribution (CC-BY) 4.0 license. 


\section{Introduction}

This research is a case study based on Softlogic Retail (Pvt) Ltd. Softlogic began as a software development company in 1991 by Mr. Ashok Pathirage with twelve employees. The company later successfully obtained the Dell authorized distributorship in Sri Lanka. Softlogic ventured into the telecommunications sector with a partnership with Dialog Axiata, offering corporate and individual Dialog GSM packages. Mr. Pathirage, who realized the potential of mobile communications, acquired the national dealership of Nokia in the year 2000. Softlogic went through a period of aggressive growth between 2006 and 2009 when they entered the retail sector with the acquisition of Uni Walkers (Pvt) Ltd. Softlogic, which has begun to diversify by entering the retail and lifestyle sectors, has opened furniture stores and showrooms island-wide. Softlogic became the authorized dealer for Panasonic, Samsung, Nokia, Dell, Apple, Candy, Russell Hobbs, and Kelvinator, adding the brand names within its fold of Consumer Electronics. The branded apparel sector was also growing, with the authorized distributor status for the jeans wear brand 'Levis' in 2009.

Later, Softlogic acquired and renovated Ceysands Hotels and Resorts jointly with the chain of hotels. They also acquired the Asiri group of hospitals as well as a large stake in the retail chain ODEL and built a 5-star, 24-story hotel with Movenpick in Colombo (Wikipedia). Softlogic Retail (Pvt) Ltd. has formed longstanding relationships with world-class, respected manufacturers and distributors of consumer electronics and is the authorized national distributor for brands such as Panasonic, Samsung, Whirlpool, Candy, Dell, Acer, TCL, and Vego, to name a few. Our broad product portfolio spans the entire technology landscape to help customers simplify their lifestyles. Our partnership with the most celebrated global consumer durable brands is the result of regular investment in our consumer research in keeping with evolving consumer demand and a changing lifestyle.

Softlogic and Softlogic Max stores stock the most recent models of televisions, home theater systems, refrigerators, washing machines, air conditioners, kitchen appliances, laptops, mobile phones, and office automation products (Softlogic.lk). Softlogic is also the authorized distributor for Panasonic Batteries and Panasonic Bulbs in Sri Lanka. Softlogic carries the following ranges of Panasonic batteries: alkaline, evolta, manganese lithium coin and rechargeable batteries. As for Panasonic Bulbs, it would be the LED bulb range. Softlogic stores also retail their own private label brands, namely Softlogic and Softlogic PRIZM TVs, and the Maximo range of home appliances that cater to the affordable durables market.

\subsection{Softlogic logistics}

In supply chain management, logistics plays the main role. To be a market leader in the industry, customer attraction and brand recognition should fulfill customer satisfaction. To maintain the two key aspects mentioned above, there should be an intelligent, fast, reliable, and interconnected logistics system. Because logistics represents the image of the company, it generally maintains a service level, and to increase the service level, there must be an existing proper current system. Softlogic Logistics can be divided into two sectors. Those are Inbound Logistics and Outbound Logistics. Procurement, including imports and exports, can be categorized under Inbound Logistics. The procurement department's role is to purchase goods and raw materials from domestic and international suppliers, select suppliers, import electronic items, etc. Outbound logistics encompasses warehouse operations (finished goods stored in own warehouse), domestic distribution (for sale), and reverse logistics (collects empties, sorts empties, stores and feeds for re-production). Domestic distribution should be very fast, and there must be an on-time delivery process to keep the service level.

\subsection{Current organizational structure}

Through our dense and extensive retail network of over 200 standard Softlogic showrooms and 22 Softlogic Max stores across the island, we strive to meet the multi-faceted customer's household wants and needs. 


\subsection{Research question}

How to develop an innovative route plan and cost model approach for the distribution of electronic products using the redistribution of vehicles in Softlogic, Sri Lanka with the minimal total cost of transportation, warehouse operation, and administration costs

\subsection{Description of the data}

Secondary data from their own SS System (Softlogic Solution System) and sales data report in Softlogic Retail (Pvt) Ltd were used for this research. Further, additional required data has been collected from annual reports, such as annual sales, monthly target demand, and chargers of each activity. This research considered one-year weekly demand.

\subsection{The significance of the research}

Redistribution is the most important and most critical process in the outbound supply chain. On the other hand, redistribution shows the image of the company and market stability. So it should be an effective process because it is a key factor in maintaining a service level. The truck allocating process is very difficult in this field. So there should be a truck allocation system to minimize the cost of transportation while maintaining the maximum service level. Truck capacity utilization directly affects the profit of the business. If redistribution process becomes critical total supply chain will break up. Currently, Softlogic Retail use decentralized distribution strategies in Sri Lanka. Because there are two distributors operating the redistribution. But through researcher research, they can allocate multi depot distribution strategies and it will help to increase service level while optimizing cost, as well as the cost of transportation.

On the other-hand, having a robust and efficient distribution and redistribution system is a main competitive advantage of the consumer electronics industry. Find the exact location according to the demand given the cost- benefit of redistributing electronic items in Sri Lanka. Appling a master plan for a distribution system in a high demand area is given a cost-benefit as well as a smooth redistribution route plan.

Through this, Multi-depot distribution strategies will help to:

- Root plan for Smooth redistribution;

- Cost optimized redistribution systems for allocating truck.

The outline of the paper is as follows: The first section summarizes the study's background, purpose, and related works. Assumptions, notations, problem statements, and model formulation are presented in section 2 . Section 3 describes how to use the newly proposed heuristic method along with the existing method and its shortcomings. Further comparative assessments are performed in this section. Finally, the conclusion and recommendation are drawn in section 4.

\subsection{Related work}

VRP can be explained as the issue of figuring out the lowest cost delivery directions or paths from a depot to a set of geographically dispersed clients, with a focus on crosswise limitations. Distribution of products and services is done by VRP in the supply chain and logistics management backdrop. This is vital for distribution management and therefore should be regularly solved by transporters. There are some modifications to the VRP that are expressed based on the nature of the goods transported, the service value, and the features of clients and vehicles. Initially, (Ami et al., 2003; Carr et al., 2002) presented the "Truck Dispatching Problem," which deals with modelling a fleet of homogeneous trucks to assist the demand for oil of number of gas stations from a central hub along with the lowest travel distance. Contributions towards rearranging this issue to a linear advanced optimization problem which generally comes across in the domain of supply chain and operational management. This can be further explained as the way of servicing a group of clients, geographically scattered around the central warehouse, utilizing the fleet of trucks with different capacities, becoming VRP, which is amongst the most broadly used phenomena in the field of Advanced Linear Programming. 
The enhancement of some forms of VRPs was found together with strategies for calculating the shortest route. (Carr \& Smelzter, 1999) defined VRP as the problem of deciding the shortest route for a vehicle that begins from one depot to ' $n$ ' number of multiple destinations to address various types of customer needs. Every vehicle that has a particular capacity begins at a depot and returns to the main depot, and furthermore, every client can only be toured once. Further, VRP offers a different range of heuristics and meta-heuristics approaches; these are introduced in (Starr, 2011; Mwikali \& Kavale, 2012) and the contributions of (Lawson et al., 2009; David et al., 2001). The VRP is broadly taken into account because of its familiar use and its significance in designing effective modes for the minimization of transportation costs in distribution systems. As a result, the goal of this paper is to create an approximation of procedures that are suitable for discovering high-quality solutions in limited time frames in the mean while addressing real-life problematic circumstances described by large vehicle fleets and influenced positively by logistics and distribution strategies.

Contemporary VRP software is being used by many public, private, and multinational companies in a large variety of industry sectors, and in particular, Coca-Cola Enterprises are generally significant (Benn, 2009; Jayarathna, 2019). The VRP has increased exponentially at a rate of $6 \%$ consistently, which creates an ubiquity for monitoring the expansions in the area and making a presentation of a strong indication of which substitutions and solution approaches are comparatively novel.

Su (2013) introduced a new VRP variant called Capacitated Vehicle Routing Problem with Pickup and Alternative Delivery (CVRPPAD), and they proposed a hybrid approach for its solution. (Mwikali \& Kavale, 2012) presented heuristic algorithms for single and multiple depot vehicle routing problems with pickups and deliveries. (Adipola,2017; Jayarathna, 2020; 2021) introduced a branch-and-price approach to address a vehicle routing problem with time windows and multiple uses of vehicles. (Mwikali \& Kavale, 2012) developed a solution approach for solving VRPTWs with constraint programming-based column generation. (Bailey, 2018) Used Column Generation algorithm to combine Constraint Programming and Linear Programming in a real-world application of bus driver scheduling. (Reck, 1988) comprehensively reviewed the existing work on the vehicle routing problem with simultaneous pickup and delivery VRPSPD, including mathematical formulations, algorithms, variants, case studies, and industrial applications. An overview of existing and emerging vehicle routing problem variants is presented (Adegoke, 2019; Suresh, 2012; Thrulogachantar \& Zailani, 2004; Tsoukas \& Knudsen, 2002, Wang, 2009, Fraering \& Prasad, 1999). Researches developed a local search heuristic approach for solving very large-scale routing problems. Demassey, Pesant, \& Rousseau (2006) and Ganepola, Jayarathna, \& Madhushani (2018) proposed three construction heuristics and an improvement procedure for solving a vehicle-routing problem arising in soft-drink distribution.

Finding the best routes for fleets to reach their customers has been the major focus of VRP (Vehicle Routing Problem), which involves calculating the lowest cost delivery directions or paths from a depot to a set of geographically dispersed clients in a crosswise manner (Harps,2019; Klaus, 2013; Kraljic, 1983; Monczka, 2009). While most of the literature has focused on inventory control within the warehouse concerning mini-applications of travel plans without having a holistic one, this research is formulated to address the issue of transportation from the warehouse to mini-hubs and from them to the retailers. While others have been concerned with plans to address the issues that arise with the expansion of the warehouse, this research focuses on finding the optimum route plan for the distribution of the goods with the hope of introducing a system that could be utilized by most industries in transporting their goods.

\section{Assumptions and notation}

The underpinning assumptions and notations of the model are as follows:

\subsection{Assumptions}

A Google map is used to find the distance between two demand points. Theoretically, the shortest distance between two points is given by a straight line between the two points. However, since consideration of such the shortest distance is impractical, it is not considered here. Instead, we consider only the Google distance value. 
Time factors, driver's behaviour, individual condition of the vehicle, and unavoidable circumstances like accidents and weather conditions, which may affect the redistribution process, are not considered.

The distance between outlets in a sub-cluster is not considered.

The rapid change in demand is not allowed.

There is no barrier to delivering goods.

Allocated trucks in a cluster deliver goods within the cluster only. None of the trucks travel between two distinct clusters.

\subsection{Notation}

The notations associated with the development of our model are listed as follows:

\subsubsection{Decision variables}

$\mathrm{R}=$ total number of depots arranged in the method;

$\mathrm{n}_{\mathrm{i}}=$ number of demand points in the $\mathrm{i}^{\text {th }}$ depot, $\mathrm{i} \in\{1,2,3 \ldots \ldots \mathrm{R}\}$;

$\mathrm{n}=$ total number of demand points in the distribution;

\subsubsection{Other parameters}

Parameters for calculate Transportation Cost (Fuel and Maintenance)

$\mathrm{G}=(\mathrm{V}, \mathrm{E})$, a graph of logistics distribution network;

$V=\left\{V_{i} / i \in\{1,2,3 \ldots \ldots . n\}\right\}$, set of nodes/vertices;

$E=\{(i, j) \mid i, j \in V, i \neq j\}$, set of arcs in which $(i, j)$ denotes the arc between node $i$ and $j$;

$\mathrm{C}_{\mathrm{i}}=$ number of clusters arranged in $\mathrm{i}^{\text {th }}$ depot;

$\mathrm{n}_{\mathrm{r}}^{\mathrm{i}}=$ number of demand points in $\mathrm{r}^{\text {th }}$ cluster at $\mathrm{i}^{\text {th }}$ depot;

$\mathrm{Q}_{\mathrm{i}, \mathrm{r}}=$ vehicle capacity of the $\mathrm{r}^{\text {th }}$ cluster at $\mathrm{i}^{\text {th }}$ depot ;

$\mathrm{q}_{\mathrm{jr}}^{\mathrm{i}}=$ weight (demand) associated with the $\mathrm{j}^{\text {th }}$ client, $\mathrm{r}^{\text {th }}$ cluster at $\mathrm{ith}^{\text {th }}$ depot;

$\mathrm{d}_{\mathrm{V}_{\mathrm{j}}}^{\mathrm{ir}} \mathrm{V}_{\mathrm{k}}=$ distance traveled from client $\mathrm{V}_{\mathrm{j}}$ to client $\mathrm{V}_{\mathrm{k}}$ in the $\mathrm{r}^{\text {th }}$ cluster at $\mathrm{i}^{\text {th }}$ depot;

$$
\text { Here } d_{V_{j}}^{i r} v_{k}=d_{V_{k} V_{j}}^{i r}
$$

$\mathrm{d}_{\mathrm{ir}}=$ total distance travelled in the $\mathrm{r}^{\text {th }}$ cluster at $\mathrm{i}^{\text {th }}$ depot;

$\mathrm{d}_{\mathrm{i}}=$ distance travel in the $\mathrm{i}^{\text {th }}$ depot vehicle;

$\mathrm{d}=$ total distance travel in all depots

$\mathrm{VC}_{\mathrm{ir}}=$ original vehicle cost for assigning in $\mathrm{r}^{\text {th }}$ cluster at $\mathrm{ith}^{\text {th }}$ depot;

$r_{i r}=$ annual depreciation ratio for vehicle assigned in $r^{\text {th }}$ cluster at $i^{\text {th }}$ depot;

$t_{i r}=$ number of years a vehicle is used in $r^{\text {th }}$ cluster at $i^{\text {th }}$ depot;

$\mathrm{R}_{\mathrm{ir}}=$ unit distance maintenance cost coefficient ratio for a vehicle used in $\mathrm{r}^{\text {th }}$ cluster at $^{\mathrm{i}^{\text {th }}}$ depot;

$\mathrm{F}_{\mathrm{ir}}=$ unit distance fuel cost coefficient ratio for a vehicle used in $\mathrm{r}^{\text {th }}$ cluster at $\mathrm{i}^{\text {th }}$ depot;

$\mathrm{AVV}_{\mathrm{ir}}^{\mathrm{t}}=$ actual vehicle value which used $t$ years in $\mathrm{r}^{\text {th }}$ cluster at $\mathrm{i}^{\text {th }}$ depot;

$\mathrm{TC}_{\mathrm{ir}}=$ transportation cost for the vehicle in $\mathrm{r}^{\text {th }}$ cluster at at $\mathrm{i}^{\text {th }}$ depot;

$\mathrm{FC}_{\mathrm{ir}}=$ fuel cost for the vehicle in $\mathrm{r}^{\text {th }}$ cluster at $\mathrm{i}^{\text {th }}$ depot;

$\mathrm{MC}_{\mathrm{ir}}=$ maintenance cost for $\mathrm{r}^{\text {th }}$ cluster at $\mathrm{i}^{\text {th }}$ depot;

$\mathrm{TC}_{\mathrm{i}}=$ transportation cost for $\mathrm{i}^{\text {th }}$ depot;

\subsubsection{Parameters for calculating warehouse operation and administration cost}

All variables defined to calculate the monthly cost

$\mathrm{K}=$ Job opportunities exist in the depot;

$\mathrm{L}=$ Number of Utilities in the depot;

$\mathrm{M}=$ Vehicle administration cost types in the depot;

$\mathrm{N}=$ Additional expenses types in the depot;

$\mathrm{W}_{\mathrm{i}}=$ Warehouse rent cost for the $\mathrm{i}^{\mathrm{th}}$ depot;

$\mathrm{S}_{\mathrm{i}}=$ Budgeted Salary of the $\mathrm{i}^{\text {th }}$ depot; 
$\mathrm{MW}_{\mathrm{i}}=$ Budgeted rental cost of the $\mathrm{i}^{\text {th }}$ depot;

$\mathrm{AE}_{\mathrm{i}}=$ Budgeted Additional cost of the $\mathrm{i}^{\mathrm{th}}$ depot ;

$S_{p}^{i}=$ Salary of the $p^{\text {th }}$ position employee at the $i^{\text {th }}$ depot; $p \in\{1,2,3 \ldots \ldots . . P\}$

$\mathrm{X}_{\mathrm{p}}^{\mathrm{i}}=1$, if $\mathrm{p}^{\text {th }}$ position employee used in the $\mathrm{i}^{\text {th }}$ depot

$X_{p}^{i}=0$, Otherwise

$E_{l}^{i}=$ expenses for the $l^{\text {th }}$ utility bill at the $i^{\text {th }}$ depot; where, $l \in\{1,2,3 \ldots \ldots . L\}$

$\mathrm{Y}_{1}^{\mathrm{i}}=1$, if $\mathrm{I}^{\text {th }}$ utility used in the $i^{\text {th }}$ depot

$\mathrm{Y}_{1}^{\mathrm{i}}=0$, Otherwise

$\mathrm{VAC}_{\mathrm{mr}}^{\mathrm{i}}=$ vehicle administrations $\mathrm{m}^{\text {th }}$ cost for $\mathrm{r}^{\text {th }}$ cluster vehicle at the $\mathrm{i}^{\text {th }}$ depot; where $m \in\{1,2,3 \ldots \ldots . M\}$

$\mathrm{Z}_{\mathrm{mr}}^{\mathrm{i}}=1$, if $\mathrm{m}^{\text {th }}$ vehicle administration cost used

$\mathrm{Z}_{\mathrm{mr}}^{\mathrm{i}}=0$, Otherwise

$A E_{n}^{i}=$ additional $n^{\text {th }}$ category expenses at the at the $i^{\text {th }}$ depot; where $n \in\{1,2,3 \ldots \ldots . N\}$

$X E_{n}^{i}=1$, if $n^{\text {th }}$ category expensus used in the $\mathrm{i}^{\text {th }}$ depot

$\mathrm{XE}_{\mathrm{n}}^{\mathrm{i}}=0$, Otherwise

TWOA = Total cost for Warehouse Operation and Administration

$\mathrm{AC}=$ Administration Cost

WOC $=$ Warehouse and Operation Cost

TTC $=$ Total Transportation Cost

TTWOA = Total cost of Transportation, Warehouse Operation and Administration

\subsection{Problem statement and model formulation}

\subsubsection{Problem statement}

This study is a case study based on Softlogic Retail (Pvt) Ltd, Sri Lanka. The company suffers from extra transportation and warehouse costs in this system due to the redundant distances generated by improper utilization of the used lorries. So, the senior management of the company wants to carry out a further investigation in order to minimize the additional transportation, warehouse operation, and administration costs incurred in the city area. Our endeavour here is in this direction.

The problem is defined as a completed directed graph $G=(V, A)$, where a tour of each cluster in each depot finishes at the destination node $V_{0}^{\mathrm{i}},\left(V_{0}^{\mathrm{i}}=V_{\mathrm{n}_{\mathrm{i}}+1}^{\mathrm{i}}\right)$. We plan to find an optimal number of clusters and depots in such a way that minimizes the total distance travelled considering all the clusters, along with the total number of vehicles and relevant clients for each of the clusters. Let each depot be ready to provide products for a fleet $C_{i}$ of vehicles with a capacity of $Q_{i, r}$, where $i \in\{1,2,3 \ldots \ldots . R\}$ and $r \in$ $\left\{1,2,3 \ldots \ldots \ldots C_{i}\right\}$. Researchers intention here is to introduce a method to minimize the total cost of transportation, warehouse operation, and administration costs. The nodes, excluding the central depots, geographically spread customers. Each customer $\mathrm{i} \in \mathrm{V}-\left\{V_{0}^{1}, V_{0}^{2}, V_{0}^{3}, \ldots . V_{0}^{\mathrm{R}}\right\}$ has certain positive demand such that $\sum_{\mathrm{j}=1}^{\mathrm{n}_{\mathrm{r}}^{\mathrm{i}}}\left(q_{j r}^{\mathrm{i}}\right) \leq \mathrm{Q}_{\mathrm{i}, \mathrm{r}}$. The distance matrix is symmetric , since $\mathrm{d}_{\mathrm{V}_{\mathrm{j}} \mathrm{V}_{\mathrm{k}}}^{\mathrm{ir}}=\mathrm{d}_{\mathrm{V}_{\mathrm{k}} \mathrm{V}_{\mathrm{j}}}^{\mathrm{ir}}$ for all $\mathrm{j}, \mathrm{k} \in$ $\left\{0,1,2,3 \ldots \ldots \ldots \mathrm{n}_{\mathrm{r}}^{\mathrm{i}}\right\}, \mathrm{i} \in\{1,2,3 \ldots \ldots . . R\}, \mathrm{r} \in\left\{1,2,3 \ldots \ldots . \mathrm{C}_{\mathrm{i}}\right\}, \mathrm{i} \neq \mathrm{j}$. The main distribution depots arrange the transportation facilities for the vehicles. That is, the distribution centre organizes each of the vehicles according to the transportation plan and the corresponding route. The vehicles start their route from the distribution depot and return to the same depot after fulfilling the requirement. This is reasonable as it is common in training that the main distribution depot can alter its vehicles to satisfy the transportation demand. Each vehicle has a load capacity limit and will incur fuel consumption, maintenance, and warehouse costs during the completion of its tasks. Thus, a distribution depot has to 
arrange transportation routes in such a way that minimizes the total transportation cost, warehouse operation, and administration cost of the whole system by taking those costs into account.

There exists a research gap between the existing VRP's and our proposed new model in this paper. Our proposed model is new in the sense that we include the transportation, warehouse operation, and administration cost incurred in the city area, which is essential to transportation practice in the new perspective of coordinating the economic costs. The solution to the model consists of designing optimal delivery and pickup routes: (1) starting and ending at the depots, (2) visiting each customer exactly once, and (3) satisfying all demands. The total cost is equal to the sum of fuel cost, maintenance cost, labour cost, warehouse operation, and all other administration costs.

This research is based on the existing Decentralized Distribution Strategy, with maintains two depots and proposes a new route plan allocation distribution Strategy. Figure 1 below shows the conceptual frame work.

\section{Figure 1: Conceptual frame work}

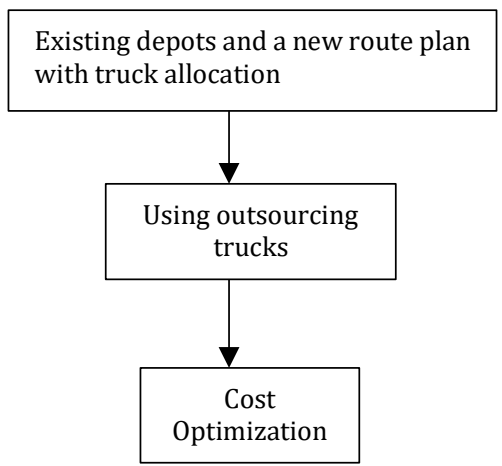

\subsection{The model formulation}

This section considers the transportation system of electronic products from a multi-depot using a group of vehicles. The distribution depots organize each vehicle with a transportation plan and route. A vehicle starts its route from the distribution depot and returns to the same after fulfilling the requirement. Assume that the number of vehicles for the said task is large enough to satisfy all the transportation demands. This is a reasonable assumption, as it is common in training that the main distribution depot can alter its vehicles to satisfy the transportation demand. Each vehicle has a load capacity limit and will incur fuel consumption and usage costs while completing its tasks. Thus, the central depot has to arrange transportation routes in a way that minimizes the total transportation, warehouse operation, and administration costs of the whole system by taking those costs into account. Thus, our proposed model in this paper, in comparison with the existing VRP models, is new in the sense that we include the fuel consumption and usage costs, which are essential to transportation practice from the perspective of coordinating the economic cost. Here, the fuel consumption cost is mainly comprised of the oil cost and the usage cost (measured by the time consumed and mainly including the depreciation cost, the operators' salaries, insurance expenses, etc.).

\subsubsection{Introduce cluster analysis vehicle routing method}

We have developed a heuristic method to solve the time-dependent vehicle routing problem. First, we form the clusters of clients based on the vehicle capacity and demand of each client. Then the optimal number of clusters along with relevant clients is found following this heuristic. finally, the total transportation cost is calculated by summing up the transportation cost of each sub-cluster. The algorithms for the heuristic methods are given below.

\section{Heuristic 1}

This heuristic procedure can be described as follows: Initially, following the gravity model formulae proposed by [1], we find the optimal location for the central depot $\left(V_{0}\right)$. Then, from the pool of 
clients (or $\mathrm{n}$ demand points), identify the nearest client $\left(\mathrm{V}_{1}\right)$ to the central depot. This can be done by taking the minimal value of the distance from the central depot to each of the clients in the distribution. Thereafter, from the remaining n- 1 number of clients, identify the next nearby client $\left(V_{2}\right)$ to $V_{1}$. This can also be done by taking the minimal value of the distance from $V_{1}$ to each of the remaining $n-1$ number of clients in the distribution. In order to see whether $V_{2}$ belongs to the same cluster containing $V_{1}$, compare the distances of $V_{2}$ from both $V_{0}$ and $V_{1}$ denoted mathematically as $d_{V_{0}} V_{2}$ and $d_{V_{1}} v_{2}$ respectively. If $d_{V_{0} V_{2}} \geq d_{V_{1} V_{2}}$ then both $V_{1}$ and $V_{2}$ belong to the same cluster. Otherwise, $V_{1}$ and $V_{2}$ do not belong to the same cluster. Next, $V_{1}$ and $V_{2}$ belong to the cluster, then identify the next nearby client $\left(V_{3}\right)$ to $V_{2}$ from the remaining $n-2$ number of clients. If $d_{V_{0} V_{3}} \geq d_{V_{2} V_{3}}$ then $V_{3}$ belongs to cluster that contains $V_{2}$. Otherwise, $V_{3}$ does not belong to that cluster. On the other hand, if $V_{2}$ does not belong to the cluster that contains $V_{1}$, then from the remaining $n-2$ number of clients, identify the next nearby client $\left(V_{3}\right)$ to $V_{1}$. If $d_{V_{0} V_{3}} \geq d_{V_{1} V_{3}}$, then $V_{3}$ belongs to cluster that contains $V_{1}$. Otherwise, $V_{3}$ does not belong to the cluster that contain $V_{1}$. Likewise we will continue the same process and identify the first cluster (containing $V_{1}$ ). Then, by using the cost formulae (1) we will calculate the total cost of fuel and maintenance of the first cluster. This process will continue to form clusters containing $V_{2}, V_{3}, \ldots$ until all the clients in the distribution are filtered into clusters.

Based on this notion, the following algorithm is developed to form clusters of clients in a distribution.

\section{Algorithm 1}

Step 01: Identify the location of the $\mathrm{n}$ demand points \& their demands.

Step 02: Consider Central location of warehouse as $\left(\mathrm{V}_{0}\right)$

Step 03: Set $\mathrm{S}_{0}=\left\{\mathrm{V}_{1}, \mathrm{~V}_{2}, \mathrm{~V}_{3}, \ldots \ldots . . . \mathrm{V}_{\mathrm{n}}\right\}, A=\emptyset$, an empty set and $\mathrm{k}=0$

Step 04: Set $\mathrm{t}=0, \mathrm{k}=\mathrm{k}+1, \mathrm{~S}_{0}=\mathrm{S}_{0} \cup A$, and define a new empty set $\mathrm{S}_{\mathrm{k}}$

Step 05: If $\mathrm{t} \leq 1$,

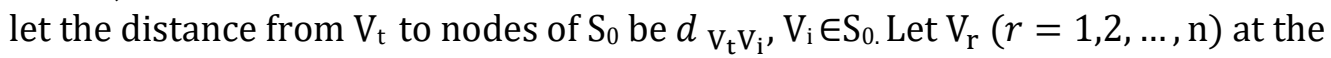

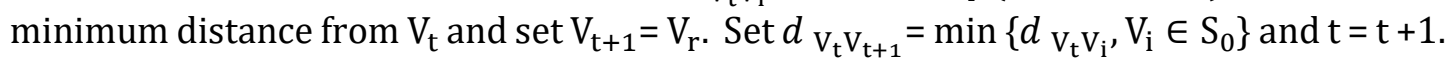

Else

let the distance from $\mathrm{V}_{l}$ to nodes of $\mathrm{S}_{0}$ be $d_{\mathrm{V}_{l} \mathrm{~V}_{\mathrm{i}}}, \mathrm{V}_{\mathrm{i}} \in \mathrm{S}_{0}$. Let $\mathrm{V}_{\mathrm{r}}(r=1,2, \ldots, \mathrm{n})$ at the

minimum distance from $\mathrm{V}_{\mathrm{t}}$ and set $\mathrm{V}_{\mathrm{t}+1}=\mathrm{V}_{\mathrm{r}}$. Set $d_{\mathrm{V}_{l} \mathrm{~V}_{\mathrm{t}+1}}=\min \left\{d_{\mathrm{V}_{l} \mathrm{~V}_{\mathrm{i}}}, \mathrm{V}_{\mathrm{i}} \in \mathrm{S}_{0}\right\}$ and $\mathrm{t}=\mathrm{t}+1$.

Step 06: If $t \leq 1$, insert $V_{r}$ to $S_{k}$, assign $V_{l}=V_{t}$ and remove $V_{r}$ from $S_{0}$ and go to Step 05.

Step 07: If $d_{\mathrm{V}_{0} \mathrm{~V}_{\mathrm{t}}} \geq d_{\mathrm{V}_{l} \mathrm{~V}_{\mathrm{t}}}$, insert $\mathrm{V}_{r}$ into $\mathrm{S}_{\mathrm{k}}$, remove $\mathrm{V}_{\mathrm{r}}$ from $\mathrm{S}_{0}$ and assign $\mathrm{V}_{l}=\mathrm{V}_{\mathrm{t}}$.

Else

insert $\mathrm{V}_{r}$ into the set $\mathrm{A}$, and remove $\mathrm{V}_{\mathrm{r}}$ from $\mathrm{S}_{0}$

Step 08: If $\mathrm{t}<\mathrm{n}$, go to Step 05

Step 09: If $A \neq \varnothing$, an empty set, go to Step 4.

Step 10: Stop.

\subsubsection{Model formulation for calculate fuel and maintenance cost of transportation}

$A V V_{i r}^{t}=V C_{i r}-\left(r_{i r}\right)^{t} V C_{i r}$, vehicle value which used $t$ years in $r^{\text {th }}$ cluster vehicle at $i^{\text {th }}$ depot ;

$\mathrm{FC}_{\mathrm{ir}}=A \mathrm{AVV}_{\mathrm{ir}}^{\mathrm{t} *} \mathrm{R}_{\mathrm{ir}} \sum_{\mathrm{j}=0, \mathrm{j} \neq \mathrm{k}}^{\mathrm{n}_{\mathrm{i}}} \min \left(\mathrm{d}_{\mathrm{V}_{\mathrm{j}} \mathrm{V}_{\mathrm{k}}}^{\mathrm{ir}}\right)$, where $\mathrm{j}, \mathrm{k} \in\left\{0,1,2,3 \ldots \ldots . \mathrm{n}_{\mathrm{i}}\right\}$

$\mathrm{MC}_{\mathrm{ir}}=\mathrm{AVV}_{\mathrm{ir}}^{\mathrm{t}} * \mathrm{~F}_{\text {ir }} \sum_{\mathrm{j}=0, \mathrm{j} \neq \mathrm{k}}^{\mathrm{n}_{\mathrm{i}}} \min \left(\mathrm{d}_{\mathrm{V}_{\mathrm{j}} \mathrm{V}_{\mathrm{k}}}^{\mathrm{ir}}\right)$, where $\mathrm{j}, \mathrm{k} \in\left\{0,1,2,3 \ldots \ldots . \mathrm{n}_{\mathrm{i}}\right\}$ respectively.

$\mathrm{TC}_{\mathrm{ir}}=\mathrm{FC}_{\mathrm{ir}}+\mathrm{MC}_{\mathrm{ir}}$

$\mathrm{TCT}_{\mathrm{i}}=\sum_{\mathrm{r}=1}^{\mathrm{C}_{\mathrm{i}}} \mathrm{TC}_{\mathrm{ir}}$, Hence the total cost over the clusters along with the constraints can

be formulated as

$$
\mathrm{TTC}=\sum_{\mathrm{i}=1}^{\mathrm{R}} \sum_{\mathrm{r}=1}^{\mathrm{C}_{\mathrm{i}}}\left[\mathrm{AVV}_{\mathrm{ir}}^{\mathrm{t}}\right] *\left[\mathrm{R}_{\mathrm{ir}}+\mathrm{F}_{\mathrm{ir}}\right] \sum_{\mathrm{j}=0, \mathrm{j} \neq \mathrm{k}}^{\mathrm{n}_{\mathrm{r}}^{\mathrm{i}}} \min \left(\mathrm{d}_{\mathrm{V}_{\mathrm{j}} \mathrm{V}_{\mathrm{k}}}^{\mathrm{ir}}\right),
$$




$$
\begin{aligned}
& \mathrm{d}_{\mathrm{ir}}=\sum_{j=0, j \neq k}^{\mathrm{n}_{\mathrm{r}}^{\mathrm{i}}} \min \left(\mathrm{d}_{\mathrm{V}_{\mathrm{j}} \mathrm{V}_{\mathrm{k}}}^{\mathrm{ir}}\right) \\
& \mathrm{d}_{\mathrm{i}}=\sum_{i=1}^{R}\left(\mathrm{~d}_{\mathrm{ir}}\right), \\
& \sum_{\mathrm{j}=1}^{\mathrm{n}_{\mathrm{r}}^{\mathrm{i}}}\left(\mathrm{q}_{\mathrm{j}}^{\mathrm{ir}}\right) \leq \mathrm{Q}_{\mathrm{i}, \mathrm{r}}
\end{aligned}
$$

Constraint (3) ensures that the total demand arises in the $r^{\text {th }}$ cluster vehicle at $i^{\text {th }}$ depot cannot exceed the vehicle capacity.

$$
\begin{aligned}
& \mathrm{n}_{\mathrm{i}}=\sum_{r=1}^{\mathrm{C}_{\mathrm{i}}}\left(\mathrm{n}_{\mathrm{r}}^{\mathrm{i}}\right) \\
& \mathrm{n}=\sum_{i=1}^{\mathrm{R}}\left(\mathrm{n}_{\mathrm{i}}\right) \\
& \mathrm{n}=\sum_{\mathrm{i}=1}^{\mathrm{R}} \sum_{\mathrm{r}=1}^{\mathrm{C}_{\mathrm{i}}} \mathrm{n}_{\mathrm{r}}^{\mathrm{i}} \\
& \mathrm{d}_{\mathrm{V}_{\mathrm{j}} \mathrm{V}_{\mathrm{k}}}^{\mathrm{ir}}+\mathrm{d}_{\mathrm{V}_{\mathrm{k}} \mathrm{V}_{\mathrm{l}}}^{\mathrm{ir}} \geq \mathrm{d}_{\mathrm{V}_{\mathrm{j}} \mathrm{V}_{\mathrm{l}}}^{\mathrm{ir}} \text { for all } \mathrm{j}, \mathrm{k}, \mathrm{l} \in\left\{0,1,2,3 \ldots \ldots \ldots n_{i}\right\} \\
& \mathrm{d}_{\mathrm{V}_{\mathrm{j}} \mathrm{V}_{\mathrm{k}}}^{\mathrm{ir}}=\mathrm{d}_{\mathrm{V}_{\mathrm{k}} \mathrm{V}_{\mathrm{j}}}^{\mathrm{ir}} \text { for all } \mathrm{j}, \mathrm{k} \in\left\{0,1,2,3 \ldots \ldots . \mathrm{n}_{\mathrm{r}}^{\mathrm{i}}\right\}, \mathrm{i} \in\{1,2,3 \ldots \ldots . \mathrm{R}\}, \mathrm{i} \neq \mathrm{j}
\end{aligned}
$$

To serve the customers, we have to design routes for a fleet with $\mathrm{C}_{\mathrm{i}}$ vehicles distributed from $\mathrm{i}^{\text {th }}$ depot, where, $i \in\{1,2,3 \ldots \ldots . R\}$. Each route must start at the depot, visit a subset of customers, and then return to the depot. All customers must be visited exactly once. This model is developed for a multi depot system but can be used for a single depot to do all cost calculations.

Finding an optimal solution to this model is a comprehensive task that requires a great amount of time for calculation ([1]). However, this type of model has economic value, especially when it is associated with integrated supply chain management. As a result, many logistics solution providers have emerged to cater to this rising demand, and these custom-made solutions are highly paid for by companies. At the same time, excel software has also been developed to facilitate accurate solutions to these mathematical models.The solution can be obtained faster and without errors by coding the objective function and all the constraints in a particular programming language.

\subsubsection{Calculation of the total warehouse operation and administration cost}

$$
\begin{aligned}
& \mathrm{TWOA}=\mathrm{AC}+\mathrm{WOC} \\
& \mathrm{TWOA}=\sum_{\mathrm{i}=1}^{\mathrm{R}} \sum_{\mathrm{p}=1}^{\mathrm{P}} \mathrm{X}_{\mathrm{p}}^{\mathrm{i}} * \mathrm{~S}_{\mathrm{p}}^{\mathrm{i}}+\sum_{\mathrm{i}=1}^{\mathrm{R}}\left[\mathrm{W}_{\mathrm{i}}+\sum_{\mathrm{l}=1}^{\mathrm{L}} \mathrm{Y}_{\mathrm{l}}^{\mathrm{i}} * \mathrm{E}_{\mathrm{l}}^{\mathrm{i}},+\sum_{\mathrm{m}=1}^{\mathrm{M}} \sum_{\mathrm{r}=1}^{\mathrm{C}_{\mathrm{i}}} \mathrm{Z}_{\mathrm{mr}}^{\mathrm{i}} * \mathrm{VAC}_{\mathrm{mr}}^{\mathrm{i}}+\right. \\
& \mathrm{AC}=\sum_{\left.\mathrm{X} \mathrm{X}_{\mathrm{n}}^{\mathrm{i}} * \mathrm{AE}_{\mathrm{n}}^{\mathrm{i}}\right]}^{\mathrm{R}} \sum_{\mathrm{p}=1}^{\mathrm{P}} \mathrm{X}_{\mathrm{p}}^{\mathrm{i}} * \mathrm{~S}_{\mathrm{p}}^{\mathrm{i}}, \\
& \mathrm{WOC}=\sum_{\mathrm{i}=1}^{\mathrm{R}}\left[\mathrm{W}_{\mathrm{i}}+\sum_{\mathrm{l}=1}^{\mathrm{L}} \mathrm{Y}_{\mathrm{l}}^{\mathrm{i}} * \mathrm{E}_{\mathrm{l}}^{\mathrm{I}},+\sum_{\mathrm{m}=1}^{\mathrm{M}} \sum_{\mathrm{r}=1}^{\mathrm{C}_{\mathrm{i}}}\left(\mathrm{Z}_{\mathrm{mr}}^{\mathrm{i}} * \mathrm{VAC}_{\mathrm{mr}}^{\mathrm{i}}\right)+\sum_{\mathrm{n}=1}^{\mathrm{N}} \mathrm{XE}_{\mathrm{n}}^{\mathrm{i}} * \mathrm{AE}_{\mathrm{n}}^{\mathrm{i}}\right],
\end{aligned}
$$




\subsubsection{Mathematical formulation to calculate the Total transportation, warehouse operation and administration cost}

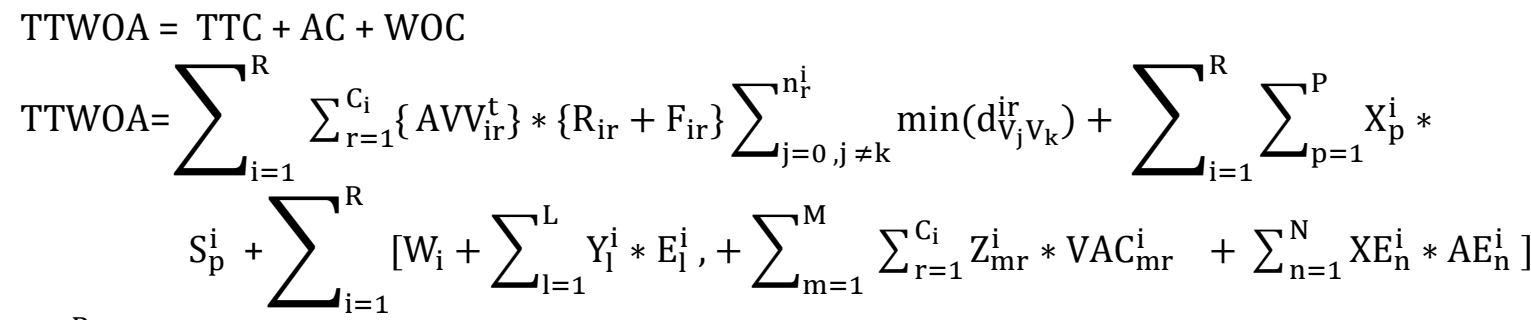

$\sum_{\mathrm{k}=1}^{\mathrm{P}} \mathrm{X}_{\mathrm{k}}^{\mathrm{i}} * \mathrm{~S}_{\mathrm{k}}^{\mathrm{i}}<\mathrm{S}_{\mathrm{i}}, \quad$ / Budget constrain for Salary of the depot;

$\mathrm{W}_{\mathrm{i}}<\mathrm{MW}_{\mathrm{i}}, \quad$ /Budget constrain for Rental cost of the depot;

$\sum_{\mathrm{n}=1}^{\mathrm{N}} \mathrm{XE}_{\mathrm{n}}^{\mathrm{i}} * \mathrm{AE}_{\mathrm{n}}^{\mathrm{i}}<\mathrm{AE}_{\mathrm{i}}, \quad$ / Budget constrain for Additional cost of the depot ;

$\sum_{\mathrm{j}=1}^{\mathrm{n}_{\mathrm{r}}^{\mathrm{i}}}\left(\mathrm{q}_{\mathrm{j}}^{\mathrm{ir}}\right) \leq \mathrm{Q}_{\mathrm{i}, \mathrm{r}}, /$ Vehicle capacity constraint of each cluster;

where $r \in\left\{1,2,3 \ldots \ldots . \mathrm{C}_{\mathrm{I}}\right\}, \mathrm{j}, \mathrm{k} \in\left\{0,1,2,3, . ., \mathrm{n}_{\mathrm{r}}^{\mathrm{i}}\right\}, \mathrm{i} \in\{1,2,3 \ldots . \mathrm{R}\}, \mathrm{p} \in\{1,2,3 \ldots \ldots . \mathrm{P}\}$, $l \in\{1,2,3 \ldots \ldots . . L\}, n \in\{1,2,3 \ldots \ldots . . N\}$

\section{Analysis of the research}

\subsection{Descriptive analysis}

Here, we provide the current approach arranged by Softlogic Retail (Pvt) Ltd to analyze the transportation, warehouse operation, and administration costs for a particular distribution of consumers, which requires clustering of customers. The company adopted a decentralized distribution system to cover the demand of 99 retail outlets through two distribution facilities (warehouses) in Piliyandala and Anuradhapura. According to the monthly sales volume obtained by the Softlogic Solution system (SSS), 1904 units (in cubic volume of $567 \mathrm{~m}^{3}$ ) will be redistributed throughout the island's wide transport system. The following table 1 shows the annual and monthly sales data of Piliyandala and Anuradhapura warehouses.

\begin{tabular}{lccc} 
Table 1: Annual sales of Sri Lanka & Annual Demand Quantity \\
\multicolumn{1}{c}{ Distribution Centre } & $\begin{array}{c}\text { Demand Quantity Per } \\
\text { (unth (units) }\end{array}$ & $\begin{array}{c}\text { Demand in Volume } \\
\left(\mathbf{m}^{\mathbf{3}} \text { ) }\right.\end{array}$ \\
\hline Piliyandala & 16864 & 1405 & 501 \\
Anuradhapura & 5989 & 499 & 66 \\
Total & $\mathbf{2 2 8 5 3}$ & $\mathbf{1 9 0 4}$ & $\mathbf{5 6 7}$ \\
\hline
\end{tabular}

\subsection{Route allocation and truck allocation model}

The researcher measured the distance between each demand point in the distribution and the existing two warehouse locations. It helps to find the relevant depot for each demand points in the distribution. Through the methodology of this research, researchers introduced a new heuristic method to arrange clusters for all demand points. If the total demand exceeds the capacity of the proposed vehicle, then it is directed to use more than one vehicle for the depot. If the total demand is too small compared to the proposed vehicle capacity, they should think about reducing cost by arranging another vehicle with capacity near the total demand of the showrooms relevant to the depot. If the total demands of all showrooms relevant to the depot exceed the vehicle capacity, then the company should find an optimal number of vehicles and the route plan of each vehicle. 


\subsection{Introduce proposed algorithm for cluster analysis on two depots}

\subsubsection{Cluster analysis based on Piliyandala}

Table 2 shows the starting and ending towns of each of the sub tours of cluster 1 relevant to Piliyandala Depot along with optimal distances travelled (google distance) and the total distance travelled inside cluster 1 (total milk run).

\begin{tabular}{lcccc}
\multicolumn{2}{l}{ Table 2: Starting and ending nodes of cluster 01- piliyandala depot } & \\
\multicolumn{1}{c}{ Starting Town } & Ending Town & $\begin{array}{c}\text { Capacity Cubic } \\
\text { Volume }\end{array}$ & $\begin{array}{c}\text { Distance } \\
\text { Travelled (Km) }\end{array}$ & $\begin{array}{c}\text { Transhipment } \\
\text { Node }\end{array}$ \\
\hline Piliyandala & Maharagama & 14 & 7 & No \\
Maharagama & Delkanda & 11 & 3 & Yes \\
Delkanda & Kohuwala & 19.3 & 3 & Yes \\
Kohuwala & Havelock & 24.6 & 5 & Yes \\
Havelock & Piliyandala & 0 & 12 & Yes \\
Total of Volume \& Distance & & 68.9 & 30 & \\
\hline
\end{tabular}

The optimal path of cluster 1 - (Piliyandala Depot) is shown in Fig. 2.

Figure 2: Optimal path of Cluster 01 - Piliyandala

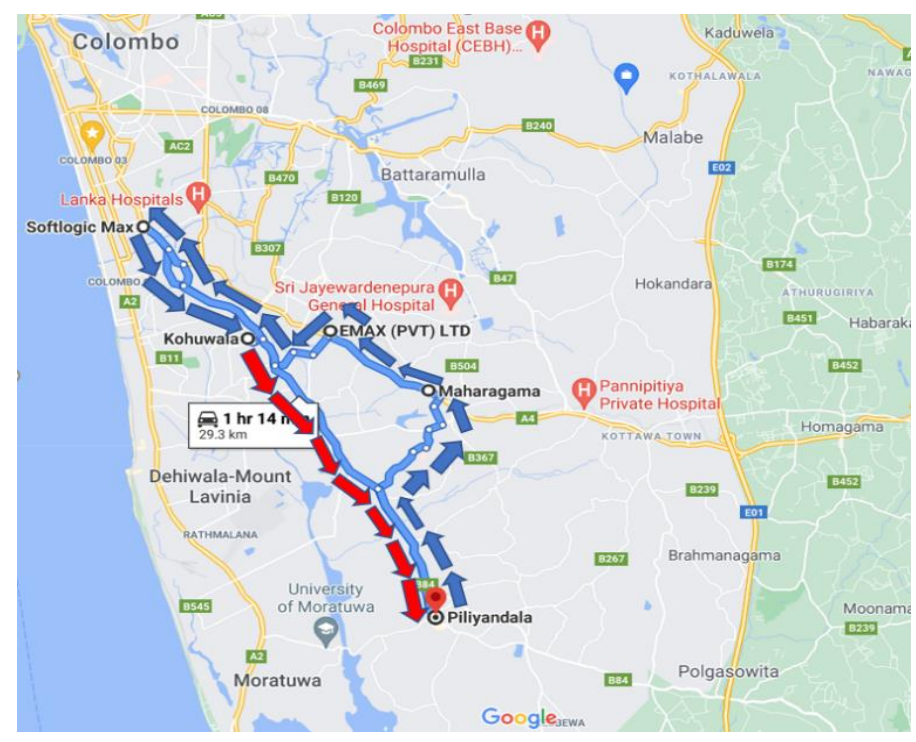

Likewise, all the milk runs of each cluster are found using the proposed routing algorithm, and Table 3 shows the results of the calculations. The below table shows the total distance travelled and the total cubic volume of each cluster.

\begin{tabular}{cccc}
\hline Table 3: Cluster arrangement of two depots & & \\
Depot & Cluster & $\begin{array}{c}\text { Total travelled distance } \\
\text { in cluster (Milk run)(km) }\end{array}$ & Capacity Cubic Volume \\
\hline \multirow{4}{*}{ Piliyandala } & Cluster 1 & 30 & 68.9 \\
& Cluster 2 & 123 & 74.6 \\
& Cluster 3 & 91 & 67.7 \\
& Cluster 4 & 523 & 75.2 \\
Anuradhapura & Cluster 5 & 62.9 & 58 \\
\hline
\end{tabular}




\subsection{Calculation the transportation cost of existing method}

Below, table 04 shows the transportation cost analysis under the existing system of Softlogic Retail (Pvt) Ltd.

\begin{tabular}{|c|c|c|c|c|c|c|}
\hline \multirow[t]{2}{*}{ Description } & \multirow{2}{*}{$\begin{array}{l}\text { Cos in } \\
(000)\end{array}$} & \multicolumn{2}{|c|}{ Piliyandala } & \multicolumn{2}{|c|}{ Anuradhapura } & \multirow[t]{2}{*}{ Monthly Cost } \\
\hline & & Quantity & $\begin{array}{c}\text { Cost } \\
(000)\end{array}$ & Quantity & $\begin{array}{c}\text { Cost } \\
(000)\end{array}$ & \\
\hline Lorry lease & 70 & 12 & 840 & 3 & 210 & 1050000 \\
\hline Lorry Insurance & 15 & 12 & 180 & 1 & 15 & 195000 \\
\hline $\begin{array}{l}\text { Insurance for } \\
\text { Goods }\end{array}$ & 35 & 12 & 420 & 1 & 35 & 455000 \\
\hline $\begin{array}{l}\text { Other } \\
\text { Transportation } \\
\text { Cost }\end{array}$ & & & 80 & & 40 & 120000 \\
\hline 14 Feet Lorry & 17.5 & 12 & 210 & 3 & 52.5 & 1050000 \\
\hline 10 Feet Lorry & 12.5 & 12 & 150 & 1 & 12.5 & 650000 \\
\hline $\begin{array}{l}\text { Dimmo Batta } \\
\text { Lorry }\end{array}$ & 10 & 12 & 120 & 1 & 10 & 520000 \\
\hline $\begin{array}{l}\text { Capacity (Cubic } \\
\text { Volume) }\end{array}$ & & & & & & \\
\hline Total & & & & & & 4040000 \\
\hline
\end{tabular}

\subsection{Calculation the total transportation cost of proposed method}

The current system of distribution is done once a week, but with the new system, delivery of goods will be done by high-capacity trucks, which means that the goods can be delivered once a month at a reduced cost, and the cost is borne by the cluster, as shown in the following cost tables below. It also includes the cost of delivery, the cost of insuring goods, the cost of employee assistance, and the cost of other items (cost of refreshment). The trucks here take a fixed price for the first 50 kilometres and charge Rs. 200 for the remaining extra per kilometre. The capacity of the prime mover is 77 cubic volumes.

Table 5 shows the total optimal distance travelled in each of the 8 clusters relevant to Piliyandala Depot. Further, the total milk run under the proposed heuristics method can be calculated, and finally, the total transportation cost of the Piliyandala Depot can be calculated.

\begin{tabular}{|c|c|c|c|c|}
\hline Description & Distance Travelled & $\begin{array}{c}\text { Fixed } \\
\text { Transportation } \\
\text { cost of the } \\
\text { cluster }\end{array}$ & $\begin{array}{c}\text { Additional } \\
\text { distance travelled }\end{array}$ & $\begin{array}{c}\text { Additional } \\
\text { Transportation } \\
\text { Cost } \\
\text { (Rs. 200 Per One } \\
\text { Kilometer) }\end{array}$ \\
\hline Cluster 01 & 30 & 35000 & 0 & 0 \\
\hline Cluster 02 & 123 & 35000 & 73 & 14,600 \\
\hline Cluster 03 & 91 & 35000 & 41 & 8,200 \\
\hline Cluster 04 & 523 & 35000 & 473 & 94,600 \\
\hline Cluster 05 & 58 & 35000 & 8 & 1600 \\
\hline Cluster 06 & 348 & 35000 & 298 & 59,600 \\
\hline Cluster 07 & 679 & 35000 & 629 & 125,800 \\
\hline Cluster 08 & 720 & 35000 & 670 & 134,000 \\
\hline \multicolumn{2}{|c|}{ Total Distance travelled } & & 2572 & \\
\hline \multicolumn{2}{|c|}{ Fixed Transportation Cost (Rs) } & & & 280,000 \\
\hline $\begin{array}{l}\text { Additional distan } \\
\text { (Rs) }\end{array}$ & Transportation Cost & & & 438,400 \\
\hline $\begin{array}{l}\text { Total Transportati } \\
\text { System (Rs) }\end{array}$ & Cost of the Proposed & & & 718,400 \\
\hline
\end{tabular}


Table 6 shows the total optimal milk run under the Propose heuristics method and Total transportation cost of the Anuradhapura Depot.

\begin{tabular}{|c|c|c|c|}
\hline Description $\quad$ Distance Travelled & $\begin{array}{c}\text { Fixed } \\
\text { Transportation } \\
\text { cost of the } \\
\text { cluster }\end{array}$ & $\begin{array}{c}\text { Additional } \\
\text { distance travelled }\end{array}$ & $\begin{array}{c}\text { Additional } \\
\text { Transportation } \\
\text { Cost } \\
\text { (Rs. 200 Per One } \\
\text { Kilometer) }\end{array}$ \\
\hline Cluster 01 & 35000 & -1685 & 337,000 \\
\hline Total Distance travelled & & 1735 & \\
\hline Fixed Transportation Cost (Rs) & & 35,000 & \\
\hline Additional distance Transportation Cost Rs) & & & 337,000 \\
\hline Total Transportation Cost of the Proposed & & & 372,000 \\
\hline
\end{tabular}

Below Table 7 shows the monthly rental cost of each warehouse.

\begin{tabular}{ccccc} 
Table 7: Rental cost on Piliyandala and Anuradhapura depot \\
\cline { 2 - 5 } & \multicolumn{2}{c}{ Piliyandala } & \multicolumn{2}{c}{ Anuradhapura } \\
\cline { 2 - 6 } & Quantity & Cost & Quantity & Cost \\
in & in & in & in \\
SQF & Rs. & SQF & Rs. \\
& $(\mathbf{0 0 0})$ & $(\mathbf{0 0 0})$ & $\mathbf{( 0 0 0 )}$ & $(\mathbf{0 0 0})$ \\
Warehouse Rent & 30000 & 1125000 & 4200 & 175000 \\
\hline
\end{tabular}

\subsection{Comparing salaries and wages in the current system and proposed system}

The study will be able to compare salaries of employees with those of staff. The below Table 8 provides the results of the existing system employee analysis and their salary with other payments.

\section{Table 8: Salary cost analysis of the existing system}

\begin{tabular}{lccc} 
& Salary in Rs & \multicolumn{2}{c}{ Existing System } \\
& & Number of & Total Cost \\
Employees & 240,0000 \\
\hline Area Manager & 80000 & 30 & 150,000 \\
Warehouse Manager & 75000 & 2 & 180,000 \\
Assistant Manager & 60000 & 3 & 210,000 \\
Warehouse Executive & 35000 & 6 & 325,000 \\
Warehouse Assistant & 25000 & 13 & 225,000 \\
Accountant & 45000 & 5 & 160,000 \\
IT executive & 40000 & 4 & 105,000 \\
Clark & 15000 & 7 & 455,000 \\
sales ref & 35000 & 13 & 900,000 \\
Lorry Drivers & 45000 & 20 & 60,000 \\
Forklift Drivers & 30000 & 2 & 128,0000 \\
Porters & 25600 & 50 & 50,000 \\
Store Porters & 25000 & 2 & $\mathbf{6 , 5 0 0 , 0 0 0}$ \\
Total & & $\mathbf{1 5 7}$ & \\
\hline
\end{tabular}

The study will be able to compare salaries of employees with those of staff. The below Table 9 provides the results of the proposed system employee analysis and their salary with other payments. 


\begin{tabular}{lccc} 
Table 9: Salary cost analysis of the proposed system & \multicolumn{2}{c}{ Proposed System } \\
& Salary in Rs & Number of Employees & Total Cost \\
\hline Area Manager & 22 & 1760,000 \\
Warehouse Manager & 80000 & 2 & 150,000 \\
Assistant Manager & 75000 & 2 & 120,000 \\
Warehouse Executive & 60000 & 4 & 140,000 \\
Warehouse Assistant & 35000 & 10 & 250,000 \\
Accountant & 25000 & 3 & 135,000 \\
IT executive & 45000 & 3 & 120,000 \\
Clark & 40000 & 8 & 120,000 \\
sales ref & 15000 & 10 & 350,000 \\
Lorry Drivers & 35000 & 0 & 0 \\
Forklift Drivers & 45000 & 3 & 90,000 \\
Porters & 30000 & 30 & 768,000 \\
Store Porters & 25600 & 2 & 50,000 \\
Total & 25000 & $\mathbf{9 9}$ & $\mathbf{4 , 0 5 3 , 0 0 0}$ \\
\hline
\end{tabular}

In the proposed system, the trucks are going to be hired with the drivers, so in the second case, the driver does not have to pay a separate salary. In the existing system, the total cost of salaries and wages is Rs 6,500,000, and in the proposed system, the total cost of salaries and wages is Rs 4,053,000.

\subsection{Total transportation, warehouse operation and administration cost based on current method and propose method}

According to Tables 8 and 9, they show the monthly cost difference between the two systems. All costs are fixed by Softlogic Retail (Pvt) Ltd., including electricity, water, and total distance kilometres. When existing system there are 157 employees work and the proposed system employee work in 99 only. And the existing system transport cost is included lorry lease, lorry insurance but the proposed system lorry lease and lorry insurance are not included. Because proposed system plans the outsource the Lorries. Below table 10 shows the cost of Total Transportation, Warehouse Operation and Administration Cost of the Existing System

\begin{tabular}{|c|c|c|c|c|}
\hline \multirow[t]{2}{*}{ Description } & \multirow[t]{2}{*}{ Cost } & \multicolumn{3}{|c|}{ Existing System } \\
\hline & & Quantity & $\begin{array}{c}\text { Total cost Per } \\
\text { week }\end{array}$ & $\begin{array}{c}\text { Total Cost Per } \\
\text { Month (Rs) }\end{array}$ \\
\hline Warehouse Rent & & & & 1300000 \\
\hline Lorry Lease & 70,000 & 15 & $\mathrm{~N} / \mathrm{A}$ & 1050,000 \\
\hline Lorry Insurance & 15,000 & 13 & N/A & 195,000 \\
\hline Insurance for Goods & 35,000 & 13 & N/A & 455,000 \\
\hline Other Expenses & & & N/A & 120,000 \\
\hline 14 Feet Lorry & 17500 & 15 & 262500 & 1050,000 \\
\hline 10 Feet Lorry & 12500 & 13 & 162500 & 650,000 \\
\hline Dimo Batta Lorry & 10000 & 13 & 130000 & 520,000 \\
\hline Electricity & & & & 115,000 \\
\hline Water & & & & 37,000 \\
\hline Holding Cost (Safety & & & & 90,000 \\
\hline \multicolumn{5}{|l|}{ Stock Cost) } \\
\hline \multicolumn{4}{|c|}{ Total Transportation and warehouse operation Cost } & 5582000 \\
\hline \multicolumn{4}{|c|}{ Total Salaries and Wedges } & $6,500,000$ \\
\hline \multicolumn{4}{|c|}{ Total Transportation, Warehouse Operation and Administration Cost } & $12,082,000$ \\
\hline
\end{tabular}

Below, Table 11 shows the cost of total transportation, warehouse operation, and administration costs of the proposed system. 


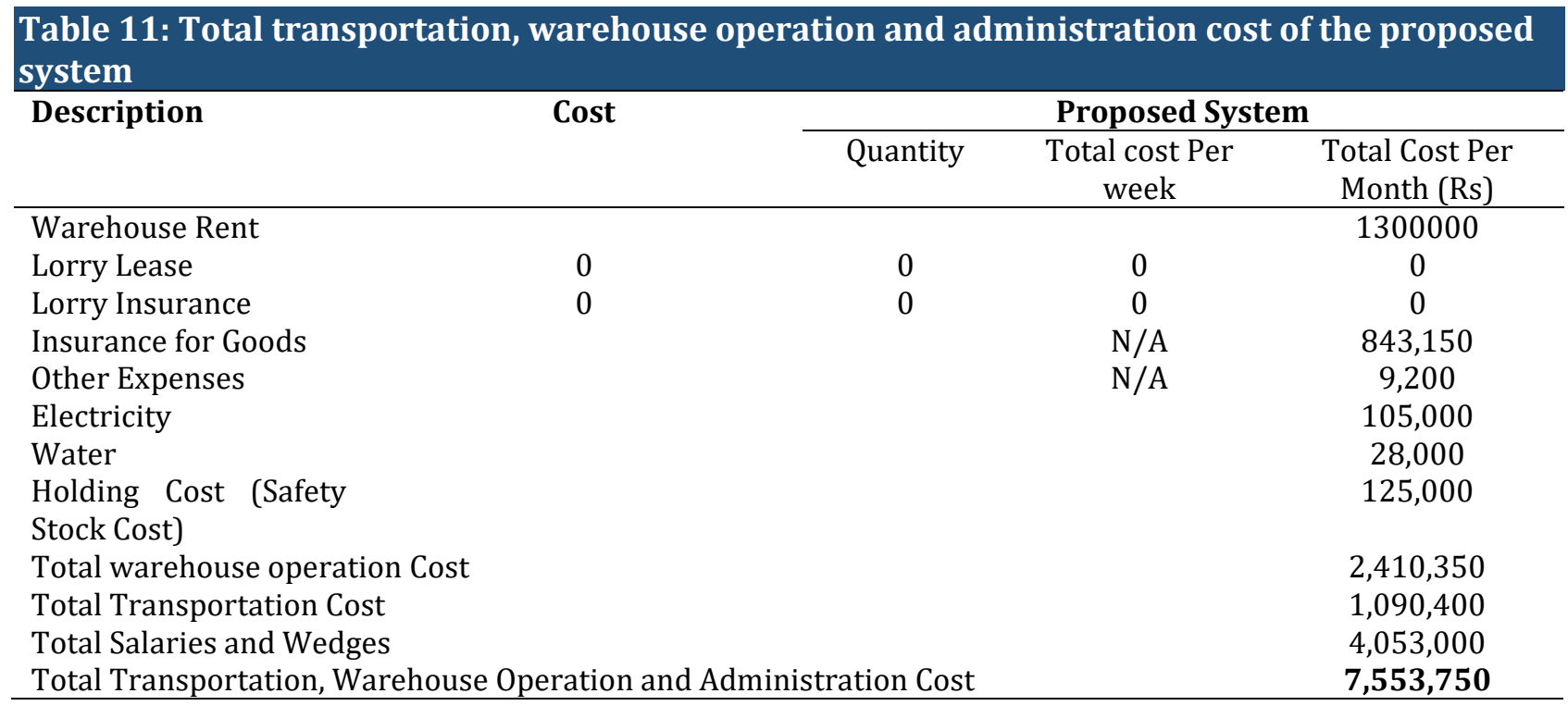

The total cost of the existing system is Rs. 12,082,000.00, but the proposed system is the proposed systems bring a saving of Rs. 7,553,750.00 per month and it is a $37.5 \%$ savings over the existing system. Below, table 12 shows the comparative study of the existing method and the proposed method.

\begin{tabular}{lc} 
Table 12: A comparative study of the existing method and proposed method \\
\hline $\begin{array}{l}\text { Total Transportation, Warehouse Operation and } \\
\text { Administration Cost for Existing System }\end{array}$ & $12,082,000$ \\
Total Transportation, Warehouse Operation and & $7,553,750$ \\
Administration Cost for Proposed System & \\
Total cost saving through new heuristic compared & $\mathbf{4 , 5 2 8 , 2 5 0}$ \\
to the Existing Model & $\mathbf{( 3 7 . 5 \% )}$ \\
\hline
\end{tabular}

\section{Conclusion and recommendation}

We developed a centralized depot strategy based on secondary data collected from Softlogic Solution System and sales data reports in Softlogic Retail (Pvt) Ltd. demand points of Sri Lanka have been divided into 99 demand regions, and the demand value of each point has been identified. A new proposed algorithm was also used to determine the best path between clusters on two depots, Piliyandala and Anuradhapura. This research has been embedded with the Central Depot capacity plan, as well as a cost comparison of the existing model and the proposed model, including transportation costs, employee salaries and wages. The computational investigation highlights the cost savings that can be induced by our proposed method. These savings can be as large as $37.5 \%$ as compared to the company's existing method. A web-based application modeling technique could be used to improve results for the problem under consideration in this paper. the future, the research scope of the problem lies in this direction.

\section{Funding}

Not applicable

\section{Conflicts of interest/Competing interests}

The authors declare no conflict of interest.

\section{Acknowledgements}

The authors thank the anonymous reviewers for their suggestions. 


\section{Citation information}

Jayarathna, D. G. N. D., Lanel, G. H. J., \& Juman, Z. A. M. S. (2021). Modeling a cost benefit transportation model to optimize the redistribution process: Evidence study from Sri Lanka. Journal of Sustainable Development of Transport and Logistics, 6(2), 43-59. doi:10.14254/jsdtl.2021.6-2.3.

\section{References}

Adegoke, O., Maltz, A., \& Christiansen, P. E. (2009). Criteria for sourcing from developing countires.Strategic Outsourcing: An International Journal, 2(2), 145-164. https://doi.org/10.1108/17538290910973367

Adipola, D. (2017). Factors affecting waste generation and ways of optimize in fast moving goods industry in Sri Lanka. Cinec Journal.

Bailey, G. (2018). IEM final projects. The concept of strategy as understood in the fields of military planning and business management. Retrieved from: http://befbattles.org.uk/pdf/methodology_2.pdf

Carr, A. S., \& Pearson, J. N. (2002). The impact of purchasing and supplier involvement on strategic purchasing and its impact on firm's performance. International Journal of Operations \& Production Management, 22(9), 1032-1053. https://doi.org/10.1108/01443570210440528

Carr, A., \& Smeltzer, R. (1999). The relationship of strategic purchasing to supply chain management. European Journal of Purchasing and Supply Management, 5(1), 43-51. https://doi.org/10.1016/S0969-7012(98)00022-7

Demassey, S., Pesant, G., \& Rousseau, L. M. (2006). A cost-regular based hybrid column generation approach. Constraints, 11(4), 315-333. https://doi.org/10.1007/s10601-006-9003-7

Fraering, M., \& Prasad, S. (1999). International sourcing and logistics: An integrated model. Logistics Information Management, 12(6), 451-460.

Fred R. David (2001). Strategic management: Concepts and cases. New Jersey: Pearson.

Ganepola, D. D., Jayarathna, N. D., \& Madhushani, G. (2018). An intelligent cost optimized central warehouse and redistribution root plan with truck allocation system in Colombo region for Lion Brewery Ceylon PLC. Journal of Sustainable Development of Transport and Logistics, 3(2), 66-73. https://doi.org/10.14254/jsdtl.2018.3-2.4

Harps, L. (2000). "The haves and the have nots": Supply chain practices for the new millenium. Inbound Logistics Journal, 75-114.

Jayarathna, D. G. N. D., Lanel, G. H. J., \& Juman, Z. A. M. S. (2019). A contemporary recapitulation of major findings on vehicle routing problems: models and methodologies. International Journal of Recent $\begin{array}{llll}\text { Technology } \text { (IJRTE), Engineering 581-585. } & \text { 8, }\end{array}$ https://doi.org/10.35940/ijrte.B1115.0782S419

Jayarathna, N., Lanel, J., \& Juman, Z. A. M. S. (2020). Five years of multi-depot vehicle routing problems. Journal of Sustainable Development of Transport and Logistics, 5(2), 109-123. https://doi.org/10.14254/jsdtl.2020.5-2.10

Jayarathna, N., Lanel, J., \& Juman, Z. A. M. S. (2021). Survey on ten years of multi-depot vehicle routing problems: mathematical models, solution methods and real-life applications. Sustainable Development Research, 3(1), 36. https://doi.org/10.30560/sdr.v3n1p36

Klaus, S. (2013). The Future Role of Civil. World Economic Forum.

Knudsen, C. S., \& Tsoukas, H. (2001). The Conduct of Strategy Research. In A. Pettigrew, H. Thomas, \& R. Whittington (Eds.), Handbook of strategy and management (pp. 413-437). SAGE Publications.

Kraljic, P. (1983). Purchasing must become supply management. Harvard business review, 61(5), 109117.

Kumar, S. N., \& Panneerselvam, R. (2012). A survey on the vehicle routing problem and its variants. Intelligent Information Management, 4(3), 66-74. https://doi.org/10.4236/iim.2012.43010

Lawson, B., Cousins, P. D., Handfield, R. B., \& Petersen, K. J. (2009). Strategic purchasing, supply management practices and buyer performance improvement: an empirical study of UK manufacturing organisations. International Journal of Production Research, 47(10), 2649-2667. https://doi.org/10.1080/00207540701694313

Monczka, R. (2009). Purchasing and Supply Chain Management: 4th edition. NY: Centage. 
Mwikali, R., \& Kavale, S. (2012). Factors affecting the selection of optimal suppliers in procurement management. International Journal of Humanities and Social Science, 2(14), 189-193.

Reck, R., \& Long, B. (1988). Purchasing: A competitive weapon. Journal of Purchasing and Materials Management, 24(3), 2-8. https://doi.org/10.1111/j.1745-493X.1988.tb00631.x

Starr, R. M. (1989). The structure of exchange in barter and monetary economies. In General Equilibrium Models of Monetary Economies (pp. 129-143). Academic Press. http://hdl.handle.net/10.2307/1880564

$\mathrm{Su}$, J. (2013). Strategic sourcing in the textile and apparel industry. Industrial Management \& Data Systems, 113(1), 23-38. https://doi.org/10.1108/02635571311289647

Thrulogachantar, P., \& Zailani, S. (2011). The influence of purchasing strategies on manufacturing performance: An empirical study in Malaysia. Journal of Manufacturing Technology Management, 22(5), 641-663. https://doi.org/10.1108/17410381111134482

Wang, H. S., \& Che, Z. H. (2007). An integrated model for supplier selection decisions in configuration $\begin{array}{llll}\text { changes. Expert } \quad \text { Systems } \quad \text { with } & \text { Applications, }\end{array}$ https://doi.org/10.1016/j.eswa.2006.02.015

World Urbanization Prospects - The 2018 Revision. (2019). Retrieved from https://population.un.org/wup/Publications/Files/WUP2018-Report.pdf.

Zeng, A. Z. (2003). Global sourcing: Process and design for efficient management. Supply Chain $\begin{array}{llll}\text { Management: } \quad \text { An } & \text { International }\end{array}$ https://doi.org/10.1108/13598540310490125

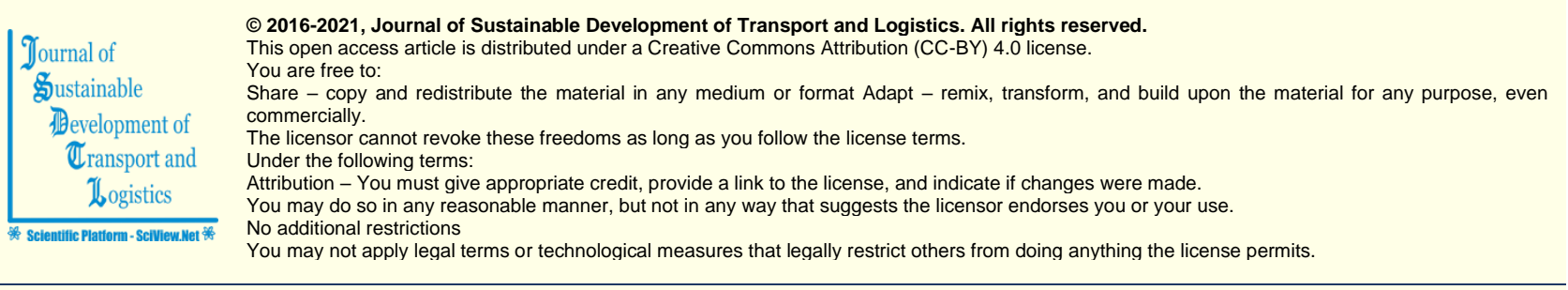

Journal of Sustainable Development of Transport and Logistics (ISSN: 2520-2979) is published by Scientific Publishing House "CSR",

Poland, EU and Scientific Publishing House "SciView", Poland, EU

Publishing with JSDTL ensures:

- Immediate, universal access to your article on publication

- High visibility and discoverability via the JSDTL website

- Rapid publication

- Guaranteed legacy preservation of your article

- Discounts and waivers for authors in developing regions

Submit your manuscript to a JSDTL at https://jsdtl.sciview.net/ or submit.jsdt|@sciview.net 